\title{
A Compact, Cylindrical Multi-pass Cell for Sensitive Detection of Gas Absorption
}

\author{
Tomokazu NISHIMOTO,$^{* *}$ Yoshihiro KATO,${ }^{2}$ Ryuta SOMEYA, ${ }^{2}$ Junichi SATO, ${ }^{2}$ Takahiro NAKAMUR, ${ }^{1}$ \\ Shigeru YAMAGUCHI, ${ }^{2}$ Kenzo NANRI, ${ }^{2}$ and Tomoo FUJIOKA ${ }^{2}$ \\ ${ }^{1}$ JASCO OPTO INC. 2967-5, Ishikawa-machi, Hachioji, Tokyo, 192-8537 \\ ${ }^{2}$ Department of Physics, School of Science, Tokai University, 1117 Kitakaname, Hiratsuka, Kanagawa, 259-1292 \\ *E-mail : tomokazu.nishimoto@jasco.co.jp
}

(Received March 10, 2008)

\begin{abstract}
We developed a compact trace gas sensor, which incorporates a cylindrical thin-disk multi-pass cell. This cell is useful because the optical path length can be selected easily in a small absorption volume across the beam path of $25 \mathrm{~cm}^{3}$. We studied the optical characteristics of this cell and demonstrated some gas measurements with this system. This paper discusses the performance of the gas detection system which incorporates a cylindrical cell.
\end{abstract}

Key Words: Laser spectroscopy, Cylindrical multi-pass cell, Gas monitor

\section{Introduction}

The demand for compact trace gas detectors is increasing in many application areas including environmental science, medical diagnostics, and industrial process control and so on. Sophisticated absorption-based spectroscopic techniques such as modulation spectroscopy, cavity ring down spectroscopy, and photo-acoustic spectroscopy have been actively studied. For most laser absorption spectroscopic devices, in which a multi-pass cell is one of the key components, a variable and long optical path length (more than $10 \mathrm{~m}$ ) and a small cell volume are desirable. There are two kinds of conventional cells, the White cells ${ }^{1)}$ and Herriot cells. ${ }^{2)}$ Optical length of White cells can be varied; however, they have a large cell volume. On the other hand, Herriot cells have a small cell volume; however their optical path length cannot be changed easily. In this paper, we report the performance characteristics of a newly proposed cylindrical thin-disk-shaped multi-pass cell that has a variable optical length with a small cell volume.

\section{Experiments}

2.1 Cylindrical multi-pass cell

Figure. 1 shows the cylindrical multi-pass cell. Spherical mirrors that are divided into six segments are placed in a circle. The mirror radius is $80 \mathrm{~mm}$. The incident light is reflected in a star configuration, and comes out when the number of reflections equals a certain number (Fig. 2). The absorption volume across the beam path is $25 \mathrm{~cm}^{3}$. As a result of this optical design, the optical path length of the cylindrical cell can be changed easily by changing the incidence angle. The relation between the incident angle and the number of reflections is given by

$$
(180+2 \theta) \times N=360 \times m
$$$$
(N=2(m-1): \text { even } N=2 m-1: \text { odd })
$$

where $\theta$ is the incidence angle and $N$ is the number of reflections. The path length changes as a function of $\theta$ as shown in Fig. 3.

When the incidence angle becomes smaller, the optical path length becomes longer. However, the beam expands with an

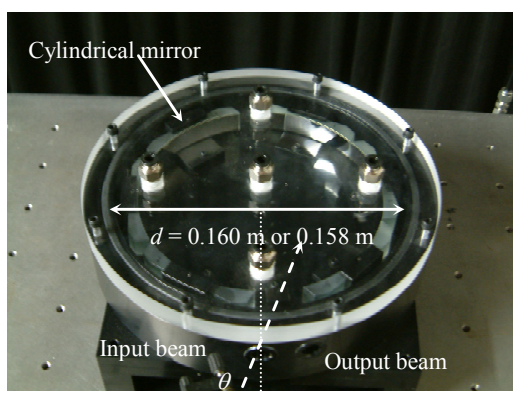

Fig. 1 Cylindrical multi- pass cell. Mirror radius is 80 $\mathrm{mm}$. The optical path length can be easily changed between $0.4 \mathrm{~m}$ and $10 \mathrm{~m}$.

increase in the number of reflections because of aberration. So,

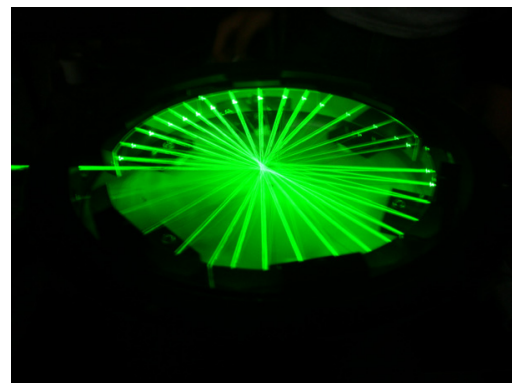

Fig. 2 Optical path trace of cylindrical cell. Incident light is reflected in a star configuration. The beam diameter could be conserved for long path lengths more than $10 \mathrm{~m}$. 


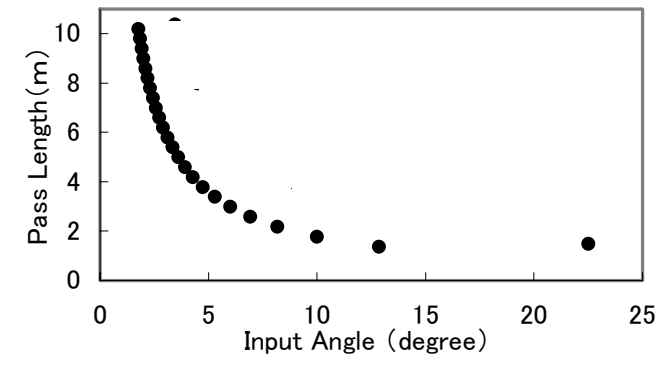

Fig. 3 Relation between the input angle and optical
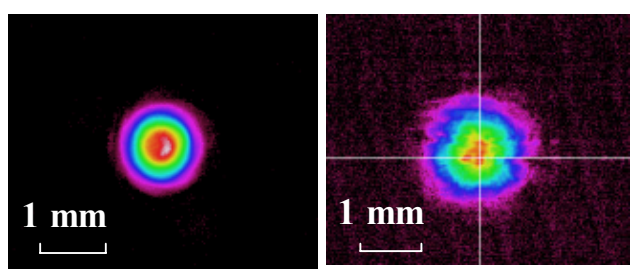

Fig. 4 Profile images of the input and output beams.

optical path length is limited. Therefore, we optimized the mirror positions on the basis of the analysis of the beam propagation, and the beam diameter was conserved for long optical path lengths of more than $10 \mathrm{~m}$. Input and output beam profile images are shown in Fig. 4.

\subsection{Experimental set-up}

A schematic of the experimental set-up is shown in Fig. 5. The set-up consists of a light source with trace gas detection and gas handling systems. We used three kinds of lasers in three respective measurements. To measure $\mathrm{CO}_{2}$ and $\mathrm{NH}_{3}$ gas mixture absorption spectra in the near-IR, a DFB-LD (NTT Electronics Inc., NLK1554STB) was operated at a wavelength of $1537 \mathrm{~nm}$ with an output power of $15 \mathrm{~mW}$ and a linewidth of less than $1 \mathrm{MHz}$. To measure $\mathrm{CO}_{2}$ absorption in a wide range, a widely tunable laser (Koshin Kogaku Co., Ltd LS-601A-56S2) was operated from $1525 \mathrm{~nm}$ to $1630 \mathrm{~nm}$ with an output power of $1 \mathrm{~mW}$ and a linewidth of less than $1 \mathrm{kHz}$. The wavelength resolution was less than $0.1 \mathrm{pm}$. To measure $\mathrm{NO}_{2}$ absorption, we used periodically poled lithium niobate $(\mathrm{PPLN})$ green $(532 \mathrm{~nm})$ laser. Each light source was aligned and passed through the cylindrical cell. The output beams were focused on photovoltaic semiconductor detectors by a

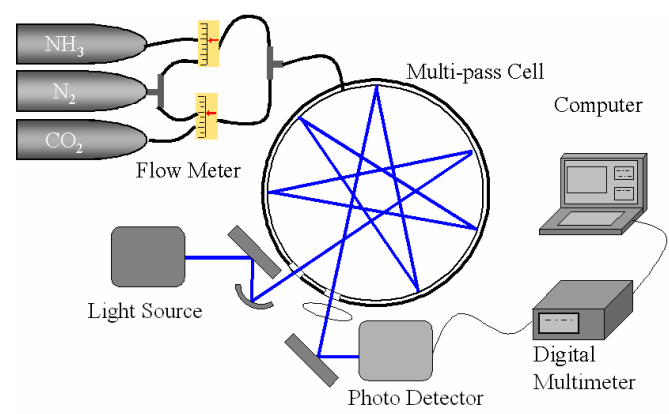

Fig. 5 Schematic of the experimental set-up. gold-coated off-axis parabolic mirror with a focal length of $50.4 \mathrm{~mm}$. The detected signal was acquired by a laptop computer with a 16-bit A/D data acquisition card (National Instruments, DAQ card-AL-16XE-50), and the signal data were analyzed using LabVIEW software. When we used DFB-LD, the absorption data were typically accumulated for 3-5 s, corresponding to $600-1000$ frequency scans. A specific gas mixing system was designed to simulate flue gas conditions. The gas handling system consisted of gas input, an optical cell, and vacuum stages. Each gas bottle containing a sample was connected to a gas bottle containing pure $\mathrm{N}_{2}$ for dilution. We could control the concentration and pressure of each sample. All gas handling lines were fabricated from stainless steel tubing.

\section{Results and Discussion}

3.1 Measurement of $\mathrm{CO}_{2}$ and $\mathrm{NH}_{3}$ absorption spectra at $1537 \mathrm{~nm}$

Figure 6 shows $\mathrm{CO}_{2}$ and $\mathrm{NH}_{3}$ gas mixture absorption spectra around $1537 \mathrm{~nm}$. The concentrations of the $\mathrm{CO}_{2}$ and $\mathrm{NH}_{3}$ gas samples were adjusted individually by mixing with pure $\mathrm{N}_{2}$ gas. We used three concentrations for each gas. The partial pressures of $\mathrm{CO}_{2}$ and $\mathrm{NH}_{3}$ were both 50 Torr. The measurement temperature was $300 \mathrm{~K}$, and the optical path length was $5.6 \mathrm{~m}$.

Although the absorption cross section of $\mathrm{CO}_{2}$ is very small in this range, we could detect this absorption. The absorption cross sections of $\mathrm{CO}_{2}$ and $\mathrm{NH}_{3}$ are $2 \times 10^{-24}$ and $6 \times 10^{-22}$ $\mathrm{cm}^{2} /$ molec, respectively. We estimated the concentrations from these result (see Table 1). Ripple noise in the multi-pass cell was not completely removed, and the intensity of this ripple noise determines the measurement limit. The detection limit of $\mathrm{CO}_{2}$ was $0.1 \%$, and that of $\mathrm{NH}_{3}$ was $30 \mathrm{ppm}$.

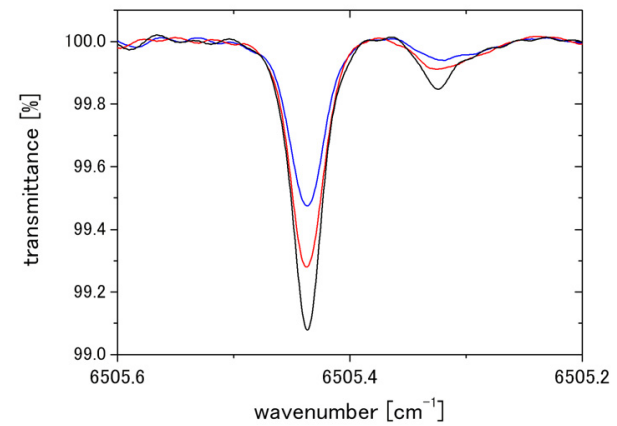

Fig. $6 \mathrm{CO}_{2}$ and $\mathrm{NH}_{3}$ gas mixture absorption spectra around $1537 \mathrm{~nm}$. We measured three concentrations in both cases. Partial gas pressure was 50 Torr each. Optical path length was $5.6 \mathrm{~m}$.

Table 1 Estimated concentrations of $\mathrm{CO}_{2}$ and $\mathrm{NH}_{3}$.

\begin{tabular}{|l|l|l|l|}
\hline & blue & red & black \\
\hline $\mathrm{CO}_{2}$ & $53.8 \%$ & $74.4 \%$ & $95.2 \%$ \\
\hline $\mathrm{NH}_{3}$ & $200 \mathrm{ppm}$ & $300 \mathrm{ppm}$ & $470 \mathrm{ppm}$ \\
\hline
\end{tabular}




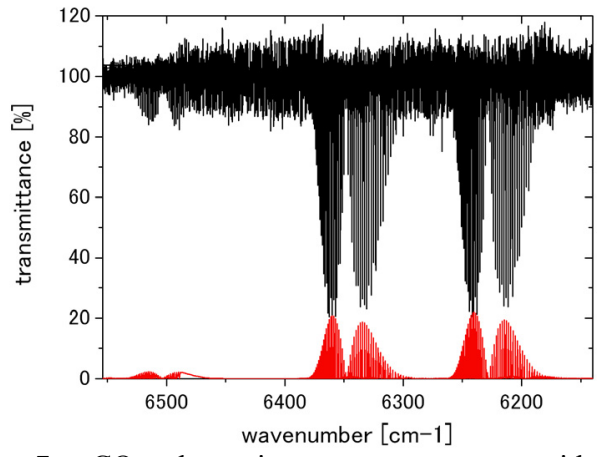

Fig. $7 \mathrm{CO}_{2}$ absorption spectra over a wide range. Experimentally observed spectra (black) and calculated ones (red) by HITRAN database. $\mathrm{CO}_{2}$ gas pressure was 200 Torr. Optical path length was $11 \mathrm{~m}$.

3.2 Measurement of $\mathrm{CO}_{2}$ absorption over a wide range

Figure 7 shows $\mathrm{CO}_{2}$ absorption spectra over a wide range. We measured from $1525 \mathrm{~nm}\left(6557 \mathrm{~cm}^{-1}\right)$ to $1630 \mathrm{~nm}(6135$ $\mathrm{cm}^{-1}$ ) continuously. The concentration of $\mathrm{CO}_{2}$ was $100 \%$ and gas pressure was 200 Torr. The measurement temperature was $300 \mathrm{~K}$. The optical path length was $11 \mathrm{~m}$. The observed spectra are shown in black, and the calculated ones by HITRAN database are shown in red. The observed and calculated spectra are in good agreement.

We can see the ripple noise. The magnitude of the ripple noise depends on the optical path length. It may be generated by interference between the light scattered on the mirror and the output light.

\subsection{Gas trace measurement of $\mathrm{NO}_{2}$ at $532 \mathrm{~nm}$}

We used this system as a gas monitor. Figure 8 shows $\mathrm{NO}_{2}$ gas trace spectra at $532 \mathrm{~nm}$. We measured $\mathrm{NO}_{2}$ at atmospheric pressure and at room temperature. The optical path length was $4 \mathrm{~m}$. Gases passed in to the cell were $\mathrm{N}_{2}$ or $\mathrm{NO}_{2}$, and was changed after a certain time.

In this system equipped with a cylindrical cell, the measurement area has a very small volume of $25 \mathrm{~cm}^{3}$, making it sensitive to the change in the concentration of gas. The response time was $30 \mathrm{~s}$. The measurement limit was $1.9 \mathrm{ppm}$ estimated by the signal-to-noise ratio

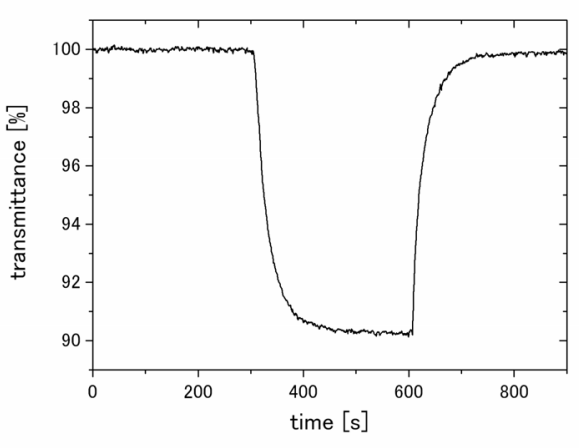

Fig. $8 \mathrm{NO}_{2}$ gas trace spectra at $532 \mathrm{~nm} . \mathrm{NO}_{2}$ gas was injected and afterwards $\mathrm{N}_{2}$ gas was injected at atmosphere pressure. Optical path length was 4 $\mathrm{m}$.

\section{Conclusion}

We investigated the performance of a cylindrical multi-pass cell. The volume of the cylindrical cell is as small as a conventional Herriot cell and its optical length could be changed easily from $0.4 \mathrm{~m}$ to more than $10 \mathrm{~m}$. The cylindrical cell has advantages over conventional cells. By measuring the absorption spectra, the performance of the cylindrical multi-pass cell were found to be comparable to that of a conventional Herriot cell. These results show that the performance of the cylindrical multi-pass cell is equivalent or superior to that of a conventional absorption cell. Specifically, it is compact and its optical path length can be easily varied.

\section{References}

1) J. U. White: J. Opt. Soc. Am. 66 (1976) 411.

2) D. Herriott, H. Kogelnik, and R. Kompfner: Appl. Opt. 3 (1964) 523.

3) W. Schneider, G. K. Moortgat, G. S. Tyndall, and J. P. Burroes: J. Photochem. Photobiol. A.40 (1987) 195

4) D. M. Sonnenfroh and M. G. Allen: Appl. Opt. 35 (1996) 4053

5) R. M. Mihalcea, D. S. Baer, and R. K. Hanson: Appl. Opt. 35 (1996) 4059 